\title{
FLOW CONTROL USING MOVING SURFACE AT THE LEADING EDGE OF AEROFOIL
}

\author{
Kh Md Faisal ${ }^{1 *}$, M A Salam², M A Taher Ali ${ }^{3}$, Md. Samad Sarkar ${ }^{4}$, Wasiul Safa $^{5}$, Nahreen Sharah ${ }^{6}$ \\ ${ }^{1-6}$ Department of Aeronautical Engineering, Military Institute of Science \& Technology, Dhaka \\ ${ }^{*}$ Corresponding e-mail: faisal@ae.mist.ac.bd
}

\begin{abstract}
Flow control is a significant topic of research in the field of aviation. Researchers in this field are continuously trying their best to find various flow control strategies in order to extract aerodynamic benefits by applying them. Applying moving surface at the leading edge of aerofoil is a type of strategy among the various types of active flow control strategies. In the present research work a rotating cylinder is added on the leading edge of the aerofoil as a moving surface in order to control the flow over its surface. The moving surface boundary layer control is applied to NACA 0018 airfoil for investigating its aerodynamic benefits and effectiveness. The moving surface is created by rotating a smooth cylinder at the leading edge of the aerofoil. The peripheral velocity of the cylinder injects momentum to the upper surface boundary layer of the aerofoil and thus delays its separation. This results in the gain in both the maximum lift coefficient and the stall angle. The work has been done at four different Reynolds Number i.e., at Re $=1.4 \times 10^{5}, 1.85 \times 10^{5}, 2.3 \times 10^{5}, 2.8 \times 10^{5}$ at different angles of attack.
\end{abstract}

Keywords: Moving surface, flow control, aerofoil, boundary layer, lift coefficient, stall sngle

\section{INTRODUCTION}

One of the most important factor for flying an aerial vehicle is the amount of lift generated during flying. The generation of lift depends mainly on the nature of deflection of the free stream air, which in turn depends on the orientation of the aerofoil and its curved shape. Due to this reason researchers are relentlessly investing efforts to find out aerofoil with improved performance which in turn gives more efficient wing. Some recent trends are flapping wing, flying wing, boundary layer suction, boundary layer blowing, vortex generator, boundary layer control etc. are some of the ways of increasing the performance of aerofoil ${ }^{1}$. Out of these methods, efforts on boundary layer suction, boundary layer blowing, and vortex generator are found in various literatures ${ }^{2-6}$. But less effort was made on investigating the influence of momentum injection on the performance of aerofoil. Recently some researches have been conducted on this topic ${ }^{7-16}$. To continue the flow of these researches, some avenues are found out according to the suggestion of previous researches. One way of this investigation is incorporating rotating cylinder at the leading edge of aerofoil which is nothing but an active flow control strategy. By this method, the advantages of momentum injection are extracted and utilized in increasing the performance of aerofoil. In aeronautics, Reynolds number $10^{5}$ constitutes an important speed regime as many unmanned aerial vehicle operates in this regime. So it is imperative to investigate aerofoil performance in this regime. But little work was done in this speed regime. Thus, this research aims for performance investigation of aerofoil having a rotating cylinder at the leading edge in the
Reynolds number range of $10^{5}$ regime. For conducting this research a symmetric aerofoil, NACA 0018 was chosen.

Performance of NACA 0018 (without rotating cylinder) were investigated and data from the modified NACA 0018 aerofoil (with rotating cylinder at the leading edge) was obtained at four different Reynolds number: $1.4 \times 10^{5}$ to $2.8 \times 10^{5}$ with zero rpm and five other rpm starting from 3000 to 5000 with an interval of $500 \mathrm{rpm}$. Results obtained through experiment were then compared with the simulation data of NACA 0018 aerofoil. This comparison showed that at lower Reynolds number (at $1.4 \times 10^{5}$ and $1.85 \times 10^{5}$ ) stall was delayed as well as maximum lift coefficient was increased while at Reynolds number $2.3 \times 10^{5}$ stall was delayed without any increment in maximum lift coefficient. Finally at Reynolds number $2.8 \times 10^{5}$ stall was little delayed with a slight decrease in maximum lift coefficient because of increase in velocity ratio as well as vibration.

\section{EXPERIMENTAL SETUP}

To analyze the effect of momentum injection on the performance of aerofoil, NACA 0018 airfoil equipped with a rotating cylinder at the leading edge of the airfoils was used.

After getting the airfoil co-ordinates, these were exported to Solidworks and designed using it. The complete wing for the wind tunnel testing was designed and constructed by wood. Measurements were checked back with reference and the wing surface was made smooth by burnishing. For experiment in this AF100 subsonic wind tunnel installed at the Applied 


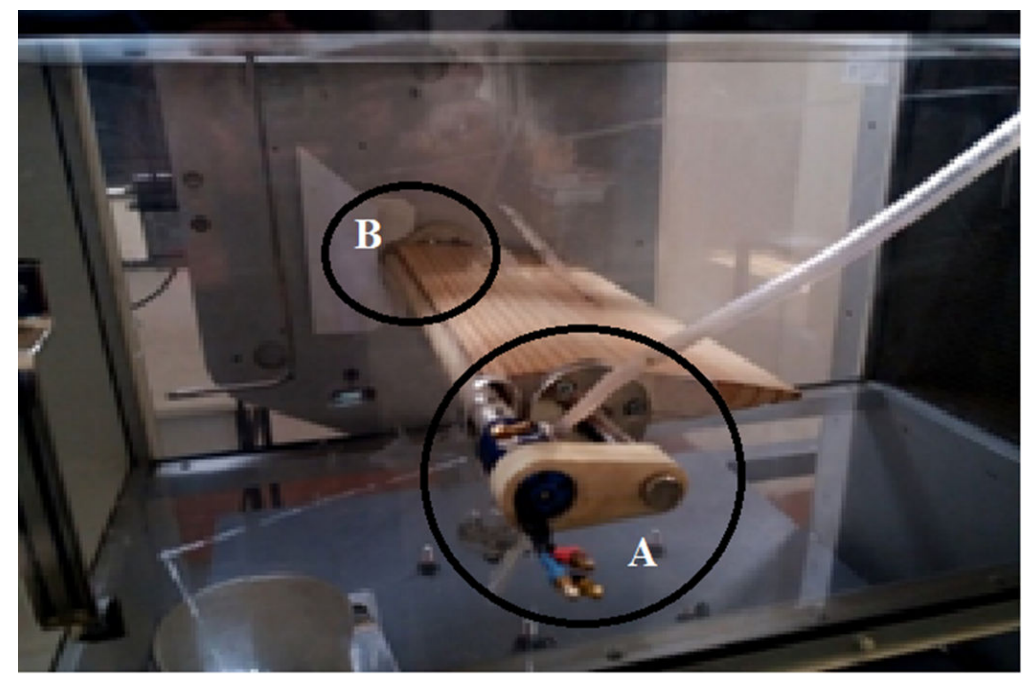

(i)

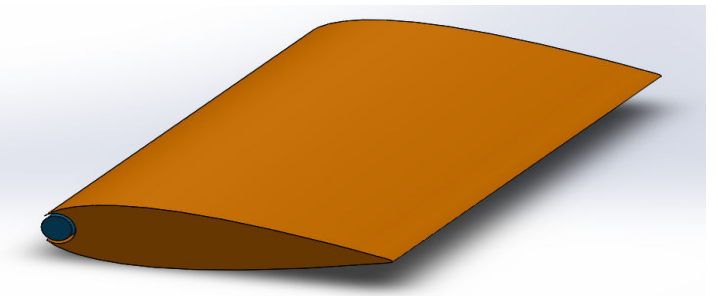

(ii)

Figure 1. (i) Experimental Setup, (ii) Schematics of NACA 0018 Airfoil with groove at the leading edge. Note: Details of Regions depicted by A and B are shown in Figures 2 and 3.

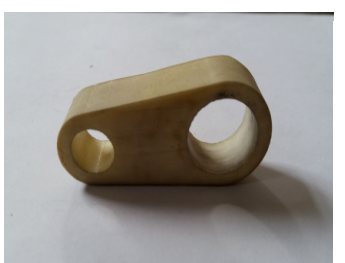

(i)

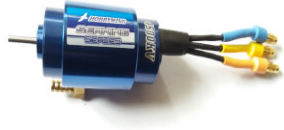

(ii)

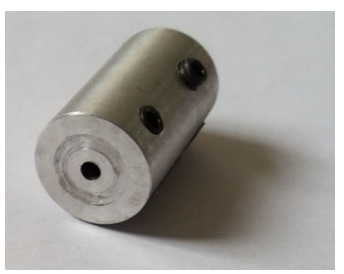

(iii)

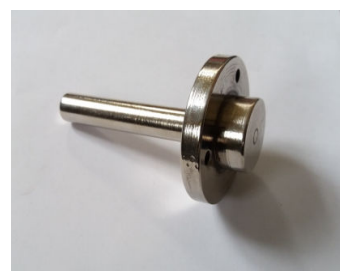

(iv)

Figure 2. Components of Region A : (i) Front connecting arm, (ii) Hobbywing Seaking 4800kv brushless motor, (iii) Coupler, (iv) Front sidewall disc

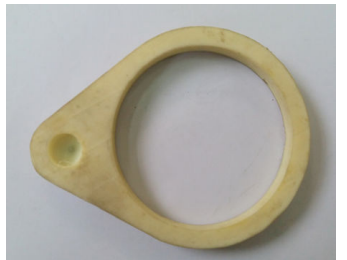

(i)

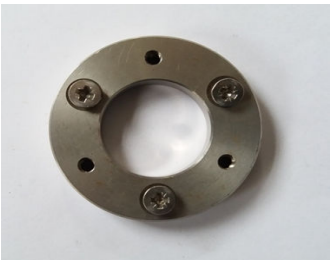

(ii)

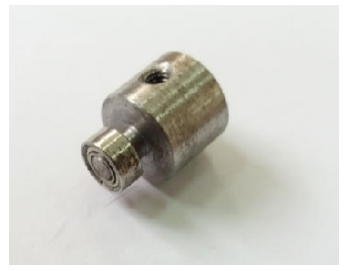

(iii)

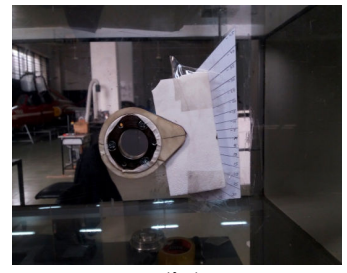

(iv)

Figure 3. Components of Region B: (i) Rear connecting arm, (ii) Rear Sidewall Disc, (iii) Cylinder Cap, (iv) Full View of Rear Section 
Aerodynamics Laboratory of Military Institute of Science \& Technology and the wing was hanged in a cantilever manner.

In this experiment, the cylinders were rotating at the leading edge of the wing. A groove was cut at the leading edge of the wing so that the cylinders could rotate at a higher rpm. Sufficient clearance was kept in order to avoid friction.

The assemblage of components of designed experimental setup is shown in Fig. 1. In this setup region A consists of front connecting arm, motor, coupler, front sidewall disc. Region $\mathbf{B}$ consists of rear connecting arm, cylinder cap and rear sidewall disc. These components are first designed in Solidworks and then fabricated using $\mathrm{CNC}$ of $\mathrm{CNC}$ Laboratory of Mechanical Engineering Department of Military Institute of Science and Technology.

The following description represents how the assembly is established: The cylinder cap is attached to the rear connecting arm. It is mounted through press fitting. The cylinder one end is connected to the cylinder cap and tighten by the plug screw on both sides. The coupler is connected to the other end of the cylinder with screws. The three component balance is required to opene to set the rear side wall connecting disc. After the disc is fixed, the connecting arm with bearing attached on it is fixed on the disc and angle is set accurately with the help of the angle measurement. Also a foam sealing is done with scotch tape to cover the groove and air leak. The motor is fixed with connecting arm and the connecting arm is inserted into the front side wall disc.

Then the three component balance is attached. From the front side wall direction, the wing is inserted and the wing is set at the same angle with the cylinder angle. The front side wall disc is also fixed with the front side wall of the wind tunnel. The motor shaft is attached to the coupler with screws. The whole assembly is shown in Fig. 1. The following equations 1 and $2^{17-18}$ are used to calculate lift coefficient and drag coefficient at various angles of attack.

Lifting Force

The lifting force acting on a body in a fluid flow can be calculated

$\mathrm{L}=1 / 2 \mathrm{C}_{\mathrm{L}} \rho \mathrm{v}^{2} \mathrm{~A}$

Drag Force

The drag force acting on a body in fluid flow can be calculated

$\mathrm{D}=\mathrm{C}_{\mathrm{D}} 1 / 2 \rho \mathrm{v}^{2} \mathrm{~A}$

where, $\mathrm{L}=$ lifting force $(\mathrm{N}), \mathrm{C}_{\mathrm{L}}=$ lifting coefficient, $\mathrm{D}=\operatorname{drag}$ force $(\mathrm{N}), \mathrm{C}_{\mathrm{D}}=\operatorname{drag}$ coefficient, $\rho=$ air density $\left(\mathrm{kg} / \mathrm{m}^{3}\right), \mathrm{v}=$ flow velocity $(\mathrm{m} / \mathrm{s}), \mathrm{A}=$ body area $\left(\mathrm{m}^{2}\right)$

The experiments were carried out in an open loop wind tunnel having test section of $0.30 \times 0.30 \times 0.60$ $\mathrm{m}^{3}$. A wind tunnel model of NACA 0018 aerofoil having chord length of $0.15 \mathrm{~m}$ with grooved leading edge was used to accommodate the rotating cylinder there. The test section was equipped with three component balance which could measure the lift force, drag force and pitching moment. The aerofoil was supported at $\mathrm{c} / 4$ chord position by a $10 \mathrm{~mm}$ rod which was mounted on support plate of the balance. The balance has the provision to place the aerofoil at different angles of attack. To support the rotating cylinder and driving motor properly at the leading edge of the aerofoil for its different angle attack, the back plate of the test section was modified. The rear end of the rotating cylinder was mounted on the bearing housed in the brackets placed at front plate and back plate of the test section. The cylinder was coupled with the driving motor with a coupler. The position of the bracket which supports the cylinder motor assembly could be changed along with the change of angle of attack of the aerofoil so that in all cases the rotating cylinder was at the leading edge of the aerofoil.

The wind tunnel fan is driven by a $380 \mathrm{~V}$ variable speed motor. The speed of the test section was varied by varying the speed of the motor and flow velocity was measured by pitot static tube and sensitive transducer whose out signal indicated velocity directly through variable data acquisition system.

\section{RESULTS AND DISCUSSIONS}

In all cases, direction of rotation was considered clockwise where the flow direction was from left to right. It was because only this direction of rotation associated with the flow direction could inject momentum on the upper surface of aerofoil.

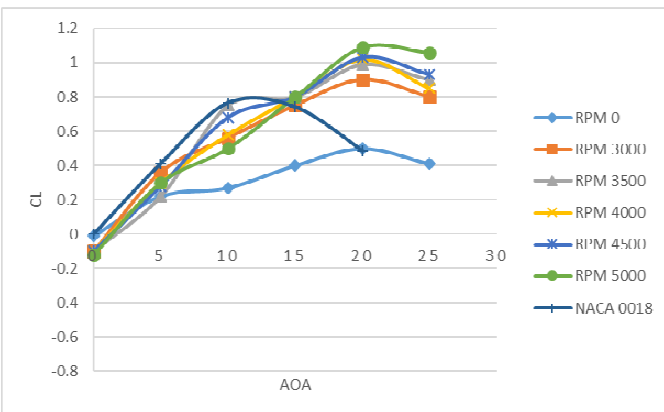

Figure 4. Effect of leading edge rotating cylinder on the lift and stall characteristics of NACA 0018 at various $\mathrm{RPM}$ at $\mathrm{V}=15 \mathrm{~m} / \mathrm{s}$.

Figure 4. represents the behaviour of modified NACA 0018 aerofoil in terms of lift coefficient and compares it with the behaviour of NACA 0018 aerofoil. The graph shows that performance of modified NACA 0018 degrades at $0 \mathrm{rpm}$ but performance improves with the introduction of rotation. The maximum lift coefficient of modified NACA 0018 increases as the $\mathrm{rpm}$ of cylinder increases. As the rpm increases the rotating cylinder at the leading edge increases the 
upstream air velocity and forces the air on the upper surface to remain attached. As a result the stall is delayed. From Figure 4. it is evident that NACA 0018 aerofoil stalls at around 12 degree at velocity $15 \mathrm{~m} / \mathrm{s}$ whether modified NACA 0018 aerofoil at the velocity stalls at 20 degree at all rpm starting from 3000 to 5000 with an interval of $500 \mathrm{rpm}$. It is also clear that as the rpm increases the value of maximum lift coefficient increases. At all rpm maximum lift coefficient of modified NACA 0018 is greater than the NACA 0018 aerofoil. As the rpm of the cylinder increases the local air velocity over the upper surface of the aerofoil increases and as the local velocity of air increases the lift coefficient also increases.

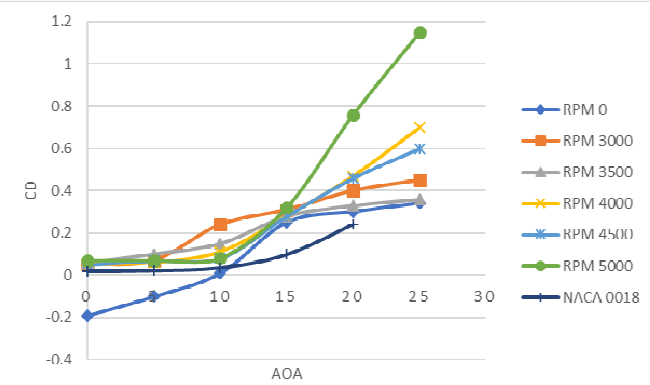

Figure 5. Effect of leading edge rotating cylinder on the drag characteristics of NACA 0018 at various RPM at $\mathrm{V}=15 \mathrm{~m} / \mathrm{s}$.

From Figure 5. it can be concluded that in almost all rpm the drag coefficient of modified NACA 0018 increases with an irregular behavior.

One phenomena worth of noticing is: at 0 and 5 degree angle of attack at $0 \mathrm{rpm}$ the $C_{D}$ value is negative. It is anticipated that this occurs due to wake generated behind the cylinder. Because of wake the pressure behind the cylinder is negative and it has a suction effect on the modified NACA 0018 aerofoil which causes it to have a tendency to move forward as a result of which the drag is negative here.

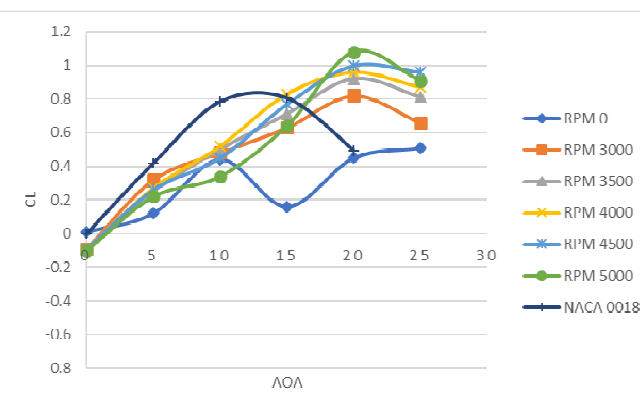

Figure 6. Effect of leading edge rotating cylinder on the lift and stall characteristics of NACA 0018 at various $\mathrm{RPM}$ at $\mathrm{V}=20 \mathrm{~m} / \mathrm{s}$.

Figure 6. represents the behaviour of modified NACA 0018 aerofoil at $20 \mathrm{~m} / \mathrm{s}$ velocity in terms of lift coefficient and compares it with the behaviour of NACA 0018 aerofoil. The graph shows that performance of modified NACA 0018 degrades at 0 rpm but performance improves with the introducing of rotation. The maximum lift coefficient of modified NACA 0018 increases as the rpm of cylinder increases. With the rpm increase, the rotating cylinder at the leading edge speeds up the upstream air and forces the air on the upper surface to remain attached. As a result the stall is delayed. From Figure 6. it is evident that NACA 0018 aerofoil stalls at around 12 degree at velocity $20 \mathrm{~m} / \mathrm{s}$ where modified NACA 0018 aerofoil at the velocity stalls at 20 degree at all rpm starting from 3000 to 5000 with an interval of $500 \mathrm{rpm}$. It is also clear that as the rpm increases the value of maximum lift coefficient increases. As the rpm of the cylinder increases the local air velocity over the upper surface of the aerofoil increases and as the local velocity of air increases the lift coefficient also increases.

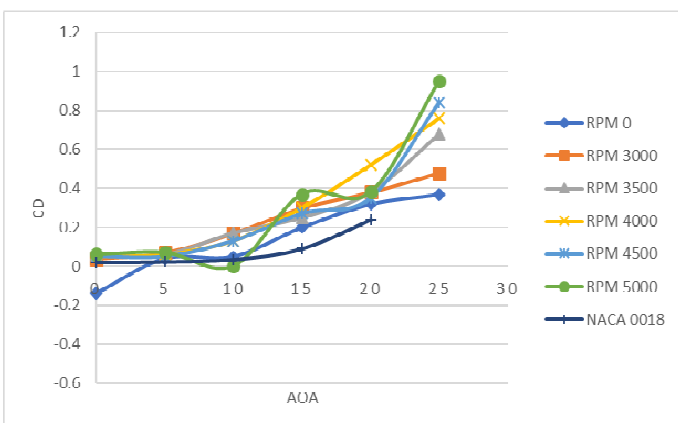

Figure 7. Effect of leading edge rotating cylinder on the drag characteristics of NACA 0018 at various RPM at $\mathrm{V}=20 \mathrm{~m} / \mathrm{s}$.

From Figure 7. it can be decided that in almost all rpm the drag coefficient of modified NACA 0018 increases. In this case also the coefficient of drag is negative here. It is for the same reason as explain earlier in the case of $15 \mathrm{~m} / \mathrm{s}$.

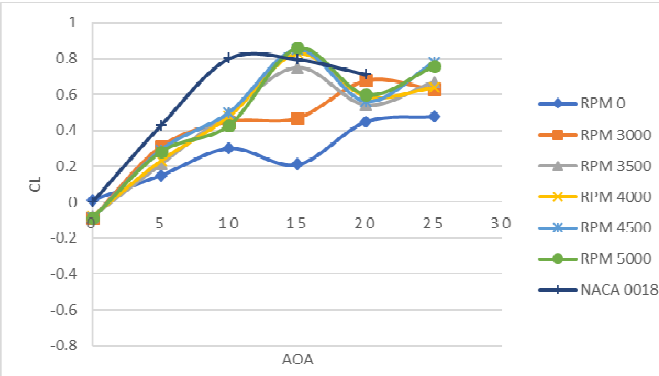

Figure 8. Effect of leading edge rotating cylinder on the lift and stall characteristics of NACA 0018 at various $R P M$ at $V=25 \mathrm{~m} / \mathrm{s}$.

Even though the modified NACA 0018 aerofoil behaves in a similar manner at Reynolds number $1.4 \mathrm{X}$ $10^{5}$ and $1.85 \times 10^{5}$ but Figure 8 . reveals that its 
behavior changes at Reynolds number $2.3 \times 10^{5}$. It is anticipated that, this occured because of the effect of vibration which becomes predominant at higher velocities.

Figure 8 . shows that modified NACA 0018 stalls at 15 degree at Reynolds number $2.3 \times 10^{5}$ while it stalled at 20 degree at Reynolds number $1.4 \times 10^{5}$ and $1.85 \times 10^{5}$ which is a major change in behaviour of modified NACA 0018 aerofoil. In addition to that, unlike the previous Reynolds numbers the $\mathrm{Cl}_{\max }$ does not surpass the $\mathrm{Cl}_{\max }$ of NACA 0018 at all rpm rather at this Reynolds number $2.3 \times 10^{5}$, only at 4000,4500 and $5000 \mathrm{rpm}$ the $\mathrm{Cl}_{\max }$ exceeds the $\mathrm{Cl}_{\max }$ of NACA 0018 aerofoil while at 0,3000 and $3500 \mathrm{rpm}$ the $\mathrm{Cl}_{\max }$ is lower than the $\mathrm{Cl}_{\max }$ of NACA 0018 aerofoil.

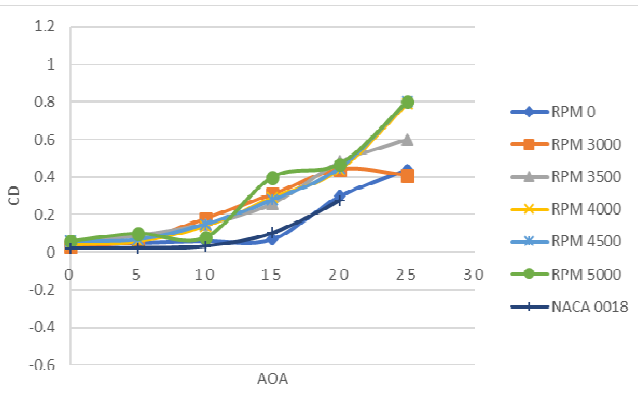

Figure 9. Effect of leading edge rotating cylinder on the drag characteristics of NACA 0018 at various RPM at $\mathrm{V}=25 \mathrm{~m} / \mathrm{s}$.

From Figure 9. it can be resolved that in almost all rpm the drag coefficient of modified NACA 0018 increases.

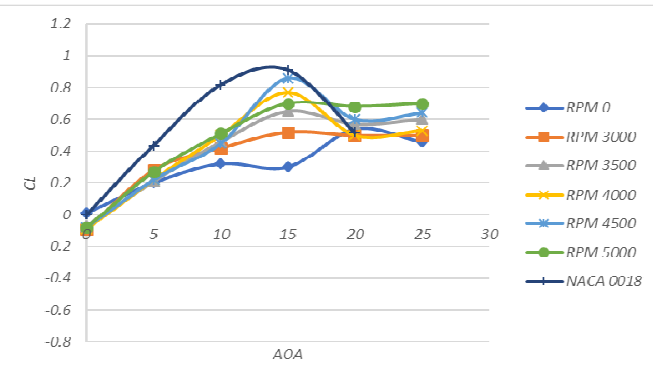

Figure 10. Effect of leading edge rotating cylinder on the lift and stall characteristics of NACA 0018 at various $\mathrm{RPM}$ at $\mathrm{V}=30 \mathrm{~m} / \mathrm{s}$.

From Figure 10. it is clear that the behaviour of NACA 0018 entirely changes at velocity $30 \mathrm{~m} / \mathrm{s}$ or at Reynolds number $2.8 \times 10^{5}$. Like the Reynolds number $2.3 \mathrm{X}$ $10^{5}$, in this case also the stall occurs at 15 degree. Unlike the behaviour of modified NACA 0018 at Reynolds number $1.4 \times 10^{5}$, at this Reynolds number at all rpm the $\mathrm{Cl}_{\max }$ is much lower than that of the NACA 0018 aerofoil. At this Reynolds number, $\mathrm{Cl}_{\max }$ increases with the increment in rpm except at $5000 \mathrm{rpm}$ at which $\mathrm{Cl}_{\max }$ decreases. At this point maximum velocity of the range of this investigation coincides with the maximum rpm which makes the vibration predominant which probably has affected the overall flow pattern, as a result of which $\mathrm{Cl}_{\max }$ decreases as well as the stall also occured earlier at $15^{\circ}$.

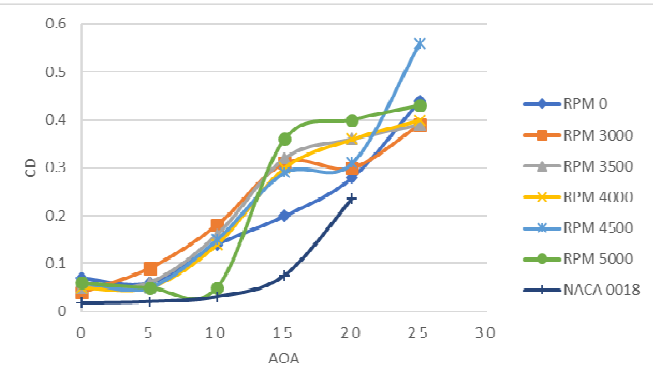

Figure 11. Effect of leading edge rotating cylinder on the drag characteristics of NACA 0018 at various $\mathrm{RPM}$ at $\mathrm{V}=30 \mathrm{~m} / \mathrm{s}$.

From Figure 11. it can be said that in almost all rpm the drag coefficient of modified NACA 0018 increases.

\section{CONCLUSIONS}

Experiments carried out in this investigation clearly defined the behaviour of modified NACA 0018 at four different Reynolds number 1.4 X $10^{5}, 1.85$ X $10^{5}, 2.3$ X $10^{5}$ and $2.8 \times 10^{5}$ which is summarized as below:

At velocity $15 \mathrm{~m} / \mathrm{s}$ or Reynolds number 1.4 X $10^{5}$ : performance of modified NACA 0018 improves both in terms of stall angle and $\mathrm{Cl}_{\max }$. Also in this case $\mathrm{Cl}_{\max }$ gradually increases with the increment in rpm. So, if the requirement of an unmanned aerial vehicle at Reynolds number $1.4 \times 10^{5}$ is such that it required stalling to be delayed with a rise in $\mathrm{Cl}_{\max }$, then this modified NACA 0018 will serve that purpose. In addition to that basing upon the change in requirement from case to case the $\mathrm{Cl}_{\max }$ can be varied also.

At velocity $20 \mathrm{~m} / \mathrm{s}$ or Reynolds number 1.85 X $10^{5}$ : Like the previous Reynolds number the performance of modified NACA 0018 improves both in terms of stall angle and $\mathrm{Cl}_{\max }$ in this case. Also in this case $\mathrm{Cl}_{\max }$ gradually increases with the increase in rpm. So, if the requirement of an unmanned aerial vehicle at Reynolds number $1.85 \times 10^{5}$ is such that it required stalling to be delayed with a rise in $\mathrm{Cl}_{\max }$ like the previous case, then this modified NACA 0018 will serve that purpose. Like the previous case $\mathrm{Cl}_{\max }$ can be varied also.

At velocity $25 \mathrm{~m} / \mathrm{s}$ or Reynolds number $2.3 \times 10^{5}$ : Unlike the previous cases in this case modified NACA 0018 exhibits improved performance in terms of stall angle but mixed performance in terms of $\mathrm{Cl}_{\max }$. Stalling occurs after 15 degree where the increment in $\mathrm{Cl}_{\max }$ takes place only at higher rpm namely 4000, 4500 and 5000. If the performance requirement is such that the unmanned aerial vehicle requires to perform variably at 
Reynolds number $1.85 \times 10^{5}$ then this modified NACA 0018 aerofoil will serve the purpose best.

At velocity $30 \mathrm{~m} / \mathrm{s}$ or Reynolds number $2.8 \times 10^{5}$ : Unlike the previous all cases, in this case $\mathrm{Cl}_{\text {max }}$ decreases compared to the NACA 0018 aerofoil. If the performance requirement is such that the $\mathrm{Cl}_{\max }$ is required to lower at all rpm then this modified NACA 0018 aerofoil will serve the purpose best. In this case $\mathrm{Cl}_{\max }$ increases with the increment in rpm except the case of $5000 \mathrm{rpm}$.

The results found that the performance of modified NACA 0018 aerofoil greater than the performance of NACA 0018baerofoil at all rotational spped at lower Reynolds number but at some rotational speeds at higher Reynolds number. It is expected that if the vibration effect can be reduced then performance of modified NACA 0018 aerofoil will exhibit superior performance both in terms of lift coefficient as well as stall angle at all rpm of all Reynolds Number. Thus rotating cylinder as a moving surface at the leading edge of aerofoil can be considered as an effective flow control strategy.

\section{REFERENCES}

1. L. J. Clancy, Aerodynamics, Pitman Publishing Limited, pp 112-113, Chapter 6, 1980, 1st Edition

2. Chang, P.K., Separation of Flow, Pergamon, pp 14-15, Chapter 3, 1970

3. Lachmann, G.V., Boundary Layer and Flow Control, Vols. 1, pp 71-72, Chapter 2, Pergamon, 1961.

4. Rosenhead, L., Laminar Boundary Layers, Oxford University Press, 1966.pp 72-73.

5. Goldstein, S., Modern Developments in Fluid Mechanics, Vols. 1, Oxford University Press, 1938, pp. 595-606.

6. Schlichting, H., Boundary Layer Theory, McGr.aw-Hill, 1968., pp. 255-257.

7. Modi V. J., Mokhtarian F., 1988, Effect of Moving Surfaces on the Airfoil Boundary-Layer Control, Journal of Aircraft, AIAA, 27-1, pp 42-50

8. Mokhtarian F., Modi V. J., 1988, Fluid dynamics of airfoils with moving surface boundary-layer control, Journal of Aircraft, AIAA, 25-2, pp 163-1696.
9. Modi V. J., Munshi S. R., Bandyopadhyay G., 1998, High-Performance Airfoil with Moving Surface Boundary Layer Control, Journal of Aircraft, AIAA, 35-4, pp 544-553

10. Modi V. J., Mokhtarian F., Fernando M. S. U. K., Moving Surface Boundary-Layer Control as Applied to Two-Dimensional Airfoils, Journal of Aircraft, AIAA, 28-2, pp 104-112. 11. 11. Bertin, J. J. Aerodynamics for Engineers. New Jersey, Prentice-Hall, Inc. Page-98, 2002.

11. Ahmed Z. Al-Garni, Abdullah M. Al-Garni, Saad A. Ahmed, Ahmet Z. Sahin, 2000, Flow Control for an Airfoil with Leading-Edge Rotation: An Experimental Study, Journal of Aircraft, AIAA, Vol-37, No-4, pp 618-623

12. Tayeb Yahiaoui, Mohamed Belhenniche and Bachir Imine, 2015, Effect of Moving Surface on NACA 63218 Aerodynamic Performance, EPJ Web of Conferences, Vol-92, No: 02114

13. Jost Seifert, 2012, A review of the Magnus effect in aeronautics, Progress in Aerospace Sciences Vol-55 No: 45, pp 17-45

14. Kavithasan Patkunam, Samay Sigamani, Pedaballi Mahathi, Selvakumaran, Oct-2015, Experimental Study of Magnus Effect over an Aircraft Wing, International Journal of Research in Engineering and Technology, Vol-4, No-10, pp 406-414

15. Kern E. Kenyon, 2016, On the Magnus Effect, Natural Science, Vol- 8, No: 52, pp 49-52

16. Timo Sailaranta, 2016, Studies on Unmanned Atmospheric Flight, Doctoral Dissertation, Department of Applied Mechanics, Aalto University, Finland, pp 40

17. Bertin, J. J. Aerodynamics for Engineers. New Jersey, Prentice-Hall, Inc. Page-98, 2002.

18. Anderson, J. D. Introduction to Flight. McGraw-Hill Companies, Inc., United States of America, 2005. pp. 150. 